OPEN ACCESS

Edited by:

Emmanuelle Canet Soulas, Université de Lyon, France

Reviewed by:

Paolo Capodaglio,

Istituto Auxologico Italiano (IRCCS),

Italy

Beat Knechtle,

University Hospital Zurich, Switzerland

${ }^{*}$ Correspondence:

John K. Smith

smithj@etsu.edu

Specialty section:

This article was submitted to

Exercise Physiology,

a section of the journal

Frontiers in Physiology

Received: 11 December 2017

Accepted: 30 April 2018

Published: 17 May 2018

Citation:

Smith JK (2018) Exercise, Obesity and

CNS Control of Metabolic

Homeostasis: A Review.

Front. Physiol. 9:574.

doi: 10.3389/fphys.2018.00574

\section{Exercise, Obesity and CNS Control of Metabolic Homeostasis: A Review}

\author{
John K. Smith* \\ Departments of Academic Affairs and Biomedical Science, James H. Quillen College of Medicine, East Tennessee State \\ University, Johnson City, TN, United States
}

This review details the manner in which the central nervous system regulates metabolic homeostasis in normal weight and obese rodents and humans. It includes a review of the homeostatic contributions of neurons located in the hypothalamus, the midbrain and limbic structures, the pons and the medullary area postrema, nucleus tractus solitarius, and vagus nucleus, and details how these brain regions respond to circulating levels of orexigenic hormones, such as ghrelin, and anorexigenic hormones, such as glucagon-like peptide 1 and leptin. It provides an insight as to how high intensity exercise may improve homeostatic control in overweight and obese subjects. Finally, it provides suggestions as to how further progress can be made in controlling the current pandemic of obesity and diabetes.

Keywords: exercise, obesity, metabolic homeostasis, hypothalamus, ghrelin, BDNF, GLP-1, leptin

\section{INTRODUCTION}

According to the World Health Organization, non-communicable diseases are the leading cause of death worldwide, causing 39.5 million deaths (70\% of total) in 2015; ischemic heart disease was the leading cause of mortality, accounting for 17.7 million or $45 \%$ of deaths. These statistics have been linked to a concomitant worldwide increase in the prevalence of obesity-associated disorders (in 2010, 18\% of children and adolescents and 39\% of adults worldwide were overweight or obese), most particularly type 2 diabetes mellitus (Chen et al., 2011; Global Health Estimates, 2015). This pandemic of nutrition-related non-communicable diseases (NR-NCD) is most striking in developing countries in which the rapid spread of supermarkets has contributed to an increased consumption of processed foods, saturated and total fats, sugar, and high caloric beverages (Demmier et al., 2017).

The current pandemic of NR-NCD has occurred in the setting a global reduction in physical activity. According to the World Health Organization, insufficient physical activity was one of the 10 leading risk factors for mortality, contributing to some 3.2 million deaths per year, and 69.3 million disability-adjusted life years in 2010 . Globally, $20 \%$ of men, $27 \%$ of women, and $78 \%$ of boys and $84 \%$ of girls aged 11-17 did not meet recommendations for exercise health (Global Health Estimates, 2015). The World Health Organization recommends that adult men and women should accumulate at least $150 \mathrm{~min}$ of moderate intensity physical activity per week and young people aged 5-17 years should accumulate at least 60 min of physical activity of moderate to vigorous intensity daily (Global Health Estimates, 2015). Of note is that exercise done by young children is much more likely to protect against adult onset obesity than exercise regimens initiated later in life (Caruso et al., 2013), and obese children are likely to become obese adults, whereas children with a healthy weight have less than a 50\% chance of becoming obese by the age of 35 (Ward et al., 2017). 
Although the scientific community is aware of life style changes that can reduce the prevalence of NR-NCD (Laslett et al., 2012), its ability to invoke non-surgical measures that lead to permanent (lifelong) reductions in weight is lacking (Merlotti et al., 2014). The challenges are considerable since, as noted by Clemmensen and associates, "modern humans have (mis)used the legacy of superior brain-power to engineer a dietary environment that supersedes peripherally derived satiation and adiposity signals, exploits the limbic system, is "unnaturally" energy-dense and hyper-palatable, and comes in virtually unlimited quantities" (Clemmensen et al., 2017).

This review is intended to provide a better understanding of the homeostatic, non-homeostatic, and hedonic nervous system pathways that contribute to obesity and its associated comorbidities, and how physical exercise may have a salutary effect when these pathways go awry.

\section{MATERIALS AND METHODS}

This best evidence review is on the effect of physical exercise on the maintenance of metabolic homeostasis. The research strategy included: 1. Defining the key topics; 2. Identifying key words or synonyms that represent each of the key topics; 3 . An online literature search of key topics and key words; and 4. A refinement of the search based on initial findings. Key topics included: global health statistics; exercise; metabolic homeostasis; obesity; diabetes mellitus; hypothalamus; orexigenic neurons, hormones and peptides; anorexigenic neurons, hormones and peptides; melanocortin system; arcuate nucleus; ventromedial nucleus; mesoaccumbens dopamine system; parabrachial nucleus; area postrema; nucleus tractus solitarius; vagus; gut-brain crosstalk; bariatric surgery; olfaction. Keywords included: exercise, obesity, metabolic homeostasis, hypothalamus, amygdala, area postrema, NTS, orexigenic, anorexigenic, ghrelin, BDNF, GLP-1, GDF15, leptin, melanocortin, NTS, POMC/CART, AgRP/NPY, vagus, bariatric surgery.

\section{CNS CONTROL OF METABOLIC HOMEOSTASIS}

\section{The Hypothalamus}

The hypothalamus is the principle regulator of the autonomic nervous system, the seasonal, and circadian clock for behavioral and sleep-wake functions, the neural center of the endocrine system, and the primary regulator of thirst and hunger. It effects these functions by communicating with other control centers in the central and peripheral nervous systems, including the prefrontal and insular cortices, the amygdala and other limbic structures, the midbrain, the pons, the medulla, and the vagus

Abbreviations: AgRP, agouti-related protein; ANS, autonomic nervous system; brain-derived neurotrophic factor, BDNF; CCK, cholecystokinin; CCK- 1R, cholecystokinin receptor 1 ; D1R, dopamine receptor type 1 ; D2R, dopamine receptor type 2; GDF15, glial-cell-derived growth and differentiation neurotrophic factor 15; GLP-1, glucagon-like peptide 1; MC3R, melanocortin 3 receptor; MC4R, melanocortin 4 receptor; NPY, neurotropin Y; NTS, nucleus tractus solitarius; pancreatic peptide, PP; peptide YY, PYY; POMC, pro-opiomelanocortin; SNS, sympathetic nervous system. and glossopharyngeal nerves. Of particular importance is the amygdaloid, whose central nucleus is a major site of origin of projections to the hypothalamus and brainstem.

\section{Arcuate and Ventromedial Hypothalamic Nuclei}

Located in the medial basal hypothalamus is the arcuate nucleus which plays an essential role in the regulation of food intake and energy expenditure (Myers and Olson, 2012; Williams, 2012; Joly-Amado et al., 2014). This nucleus contains orexigenic neurons that co-express agouti-related protein and neuropeptide Y (AgRP/NPY neurons) and anorexigenic neurons co-expressing pro-opiomelanocortin and cocaine and amphetamine-regulated transcripts (POMC/CART neurons). Unlike other hypothalamic nuclei, the arcuate nucleus is located outside the blood-brain barrier and thus is ideally situated to receive input from circulating nutrients and hormones; it also receives signals emanating from cerebrospinal fluid bathing the third ventricle (Williams, 2012).

AgRP/NPY expressing neurons enhance appetite and weight gain by $\gamma$-aminobutyric acid (GABA)-mediated tonic inhibition of POMC/CART neurons including the suppression of anorexigenic signals from neurons located in the parabrachial nucleus of the pons. The anorexigenic effects of the parabrachial nucleus come from glutaminergic signals originating in the nucleus tractus solitarius in the medulla which services the vagus nerve (Wu et al., 2012). Both insulin and leptin suppress appetite and weight gain by inhibiting AgRP/NPY neurons, and insulin action on these neurons suppresses hepatic gluconeogenesis, contributing to glycemic control (Myers and Olson, 2012). The orexigenic hormone ghrelin, which is produced by endocrine cells in the gastric mucosa, enhances food intake by activating AgRP/NPY neurons (Mason et al., 2014). Ghrelin also regulates synaptogenesis between AgRP/NPY and POMC/CART neurons (Williams, 2012). In experimental animals, obliteration of arcuate AgRP/NPY neurons results in loss of appetite, progressive weight loss and, eventually, death due to starvation (Carter et al., 2013).

POMC/CART expressing neurons produce $\alpha$-melanocyte stimulating factor which on binding to melanocortin-3 (MC3R) and melanocortin-4 (MC4R) receptors promotes energy expenditure and suppresses food intake. MC3R are expressed at high levels in the ventromedial and arcuate nuclei, whereas MC4R are widely spread throughout the central nervous system, most notably in the ventromedial nucleus (Myers and Olson, 2012). POMC/CART neurons are inhibited by NPY and activated by leptin, serotonin, brain-derived neurotrophic factor (BDNF), and glial-cell-derived growth and differentiation neurotrophic factor 15 (GDF15), a divergent member of the transforming growth factor (TGF)- $\beta$ superfamily (Williams et al., 2011; Macia et al., 2012; Spaeth et al., 2012; Fox et al., 2013; Tsai et al., 2014; Clemmensen et al., 2017). In experimental animals, obliteration of POMC/CART neurons in the ventromedial nucleus leads to morbid obesity (Macia et al., 2012).

Liu et al. provided evidence in mice that glucagon-like peptide-1 (GLP-1) expressing neurons in the medulla send anorexigenic signals to the paraventricular nucleus (PVN) of the 
hypothalamus and that postnatal depletion of GLP-1 receptors in the PVN causes hyperphagic obesity (Liu et al., 2017). GLP1 is a potent incretin, and regulates glucose independent of its anorexigenic effects (Näslund et al., 2004).

Activation of the sympathetic nervous system by melanocortin receptors in the ventromedial nucleus enhances energy expenditure by increasing thermogenesis and fatty acid utilization in skeletal muscle and brown adipose tissue (Gavini et al., 2016). In this regard, neurons in the olfactory epithelium and bulb have a high density of receptors for insulin, leptin and ghrelin, and, because of an incomplete blood-brain barrier, the bulb has access to circulating levels of hormonal and nutrient signals in a manner similar to the arcuate nucleus; bulb signals are transmitted to the hypothalamus via pathways in the pyriform cortex and amygdala and increase energy expenditure by enhancing thermogenesis in brown adipose tissue. (Garrison and Knight, 2017).

\section{Area Postrema, Nucleus Tractus Solitarius, and Vagus}

The area postrema, a brainstem organ analogous to the hypothalamic arcuate nucleus, receives and integrates multiple metabolic signals, including anorexigenic signals from leptin, cholecystokinin, amylin, GLP-1, pancreatic peptide (PP) and peptide YY (PYY), and orexigenic signals from ghrelin (Wren, 2008; Clemmensen et al., 2017). This area projects to the nucleus tractus solitarius (NTS) which also receives continuous input from vagal afferent fibers located in the intestinal wall and gastric mucosa including those that relay information on the volume and composition of food being ingested (Clemmensen et al., 2017). As previously noted, the NTS relays these signals to the parabrachial nucleus in the pons. In turn, calcitonin gene-related peptide expressing neurons in the parabrachial nucleus send anorexigenic signals to the arcuate nucleus and central amygdala (Carter et al., 2013). Like the amygdala, the parabrachial nucleus helps place an emotional stamp on taste (e.g., taste aversion, taste preference). GLP-1 expressing neurons in the nucleus tractus solitarius relay anorexigenic signals to corticotrophin-releasing hormone $(\mathrm{CRH})$, nefstatin-1, and oxytocin-expressing neurons in the paraventricular nucleus (Katsurada et al., 2014). GLP-1 receptor binding has been shown to restrict feeding by enhancing the strength of excitatory synaptic signals in paraventricular CRH neurons via a protein kinase A-dependent signaling cascade (Liu et al., 2017). The BDNF receptor TrkB is highly expressed in neurons in the area postrema, nucleus tractus solitarius, and dorsal motor nucleus of the vagus; evidence suggests that TrkB signaling in the NTS mediates the anorexigenic effects of brainstem BDNF (Spaeth et al., 2012).

The area postrema and NTS also contribute to nonhomeostatic body weight regulation by expressing receptors for GDF15 (GDF15AL). GDF15LA ligation transmits anorexigenic signals to neurons located in the parabrachial and central amygdala nuclei. This pathway causes anorexia and weight loss in disorders associated with tissue stress or injury (Tsai et al., 2014; Hsu et al., 2017), and has been shown to decrease food intake, body weight, and improve glucose tolerance in mice on normal and obesogenic diets (Macia et al., 2012; Tsai et al., 2017). GDF15 is also known as macrophage inhibitory cytokine-1 (MIC-1) (Tsai et al., 2014).

By communicating with neurons in the NTS, vagal neurons expressing receptors for gut-derived hormones play a significant role in appetite regulation. GLP-1 binding induces an anorexigenic phenotype in afferent vagal neurons, an effect that is down-regulated by ghrelin (Ronveaux et al., 2015); and cholecystokinin-induced inhibition of food intake is dependent on signaling from vagal afferent neurons. Importantly, vagus afferent neurons can change their phenotype and express either orexigenic or anorexigenic receptors depending on the availability of nutrients (Ronveaux et al., 2015).

\section{Midbrain and Limbic System}

As noted, taste aversions and taste preferences are mediated in part by nuclei located in the central amygdala. However, food reward signals are mediated primarily by midbrain dopaminergic neurons that project rostrally to the nucleus accumbens (the mesoaccumbens dopamine system) and then to other areas in the limbic system, ultimately reaching the prefrontal cortex where conscious decisions regarding eating are made (Clemmensen et al., 2017). Importantly, growth hormone secretagogue receptors (GHSRs) in dopaminergic neurons mediate ghrelin-induced homeostatic feeding and ghrelin-engaged food-reward behavior. And GHSRs in the hippocampus and amygdala mediate more complex behaviors related to food intake, including cue-potentiated feeding (Mason et al., 2014).

\section{OBESITY AND METABOLIC HOMEOSTASIS}

\section{The Hypothalamus}

The ability of the hypothalamus to control energy balance is "compromised and degraded" in the majority of obese individuals (Williams, 2012). Aberrant functioning can be found at many levels, including the integration of signals of satiety and the regulation of glucose and lipid metabolism. In addition, there is a mechanistic link between over-eating, particularly of long chain fatty acids, and the occurrence of systemic inflammatory responses that can degrade the functioning of the hypothalamus in obese individuals (Arkan et al., 2005; Williams, 2012; de Git and Adan, 2015).

\section{Arcuate and Ventromedial Hypothalamic Nuclei \\ Studies in Rodents}

In rats, high-fat, high-energy feeding has been shown to cause resistance to the anorexic and thermogenic effects of leptin due to reduced mRNA expression and transduction capabilities of the long form of the leptin receptor in arcuate nuclei (Patterson et al., 2009). High fat diets have also been shown to reduce synapses on POMC neurons (Horvath et al., 2010), and suppression of neurogenesis is reported to occur in the arcuate nuclei of mice with diet or leptin deficiency-induced obesity (McNay et al., 2012). Baver and associates have shown that diet-induced obesity 
in mice is associated with a failure of leptin to inhibit the orexigenic effects of AgRP neuronal activity (Baver et al., 2014).

\section{Studies in Humans}

Humans with single nucleotide polymorphisms in the MC4R are morbidly obese, hyperphagic, and have elevated leptin levels and insulin resistance (Haskell-Luevano et al., 2009); those with deficiencies in the leptin or leptin receptor gene, or BDNFrelated genetic polymorphisms also have hyperphagic obesity (Spaeth et al., 2012). Although blood levels of leptin increase in proportion to the triglyceride content of white adipose tissue, obese humans have reduced sensitivity to its anorexigenic effects; this resistance is incompletely understood but may be the consequence suppressor-of-cytokine-signaling (SOCS-3) blocking the central effects of leptin (Greenberg and Obin, 2006). Fasting ghrelin levels in children with the Prader-Willi syndrome are elevated and may play a role in their insatiable appetite whereas fasting levels in both normal and obese individuals are inversely related to their body mass index (Haqq et al., 2003). And serum levels of BDNF are reported to be depressed in obese subjects with type 2 diabetes (Li et al., 2016).

\section{Area Postrema, Nucleus Tractus Solitarius, Parabrachial Nucleus, and Vagus Studies in Rodents}

In mice, high-fat, high-energy feeding is reported to impair anorexigenic signals in the caudomedial nucleus of the NTS (Cavanaugh et al., 2015), and to alter circadian expression of molecular clock genes in this nucleus (Kaneko et al., 2009). Treatment with GDF15, which binds to neurons in the NTS, the area postrema, and the arcuate nucleus, has been shown to decrease adiposity and correct metabolic function in dietinduced obese mice (Tsai et al., 2017).

Zhang and associates found that pro-opiomelanocortin gene transfer to the NTS but not to the arcuate nucleus ameliorates diet-induced obesity in rats, emphasizing the critical role that the NTS plays in energy regulation (Zhang et al., 2010). And Kovacs and Hajnal found that obese rats lacking cholecystokinine1 receptors had fewer sucrose-responsive neurons in the parabrachial nucleus and an overall reduction in taste response magnitude to sucrose when compared to lean animals (Kovacs and Hajnal, 2008).

Administration of native GLP-1 and GLP-1 agonists such as exendin-4 and liraglutide have been shown to reduce food intake and weight in obese rodents by inducing anorexigenic phenotype switching in afferent vagal neurons; unlike its analogs, native GLP-1 is rapidly degraded in the circulation, limiting its potential as a therapeutic agent (Ronveaux et al., 2015).

\section{Studies in Humans}

Plasma GLP-1 levels are reported to be low in obese individuals with normal and impaired glucose tolerance (Hussein et al., 2014), and administration of native GLP-1 and GLP-1 agonists have been shown to reduce food intake and weight in obese humans (Näslund et al., 2004). GLP-1 is the most powerful known incretin (i.e., insulin releaser) in humans and serves as the basis for recent treatments of diabetes. Acute high intensity exercise has been shown to increase GLP-1 levels and reduce hunger scores in obese subjects, although the rise was less than that seen in normal weight subjects (Ueda et al., 2013).

In his review of the therapeutic effects of obesity surgery, Blasi notes the rapid and often persistent remission of type 2 diabetes and the metabolic syndrome following bariatric surgery, and reviews the major role that the vagal NTS and vaso-vagal pathways play in restoring normal function to the pancreas (normalizing insulin secretion, reducing glucagon production), liver (recovering insulin sensitivity, reducing gluconeogenesis and free fatty acid release), and gastrointestinal tract (reducing ghrelin secretion, restoring normal responses to nutrients, peptides, hormones) (Blasi, 2016).

\section{Midbrain and Limbic System Studies in Rodents}

The inactivity characteristic of obesity is associated with reductions in dopamine receptor signaling in the mesoaccumbens dopamine system, most notably from $\mathrm{D}_{2} \mathrm{R}^{+}$ neurons in the nucleus accumbens (Zhu et al., 2016; Ruegsegger and Booth, 2017). Voluntary wheel running in obese rats is reported to attenuate the metabolic syndrome in MC4R deficient rats with dopamine dysregulation even though the reward signals are blunted; MC4R are highly expressed by dopamine secreting neurons in the mesolimbic dopamine pathway (Obici et al., 2015).

Mice rendered hyposmic by ablation of olfactory nerves have been shown to be resistant to diet-induced obesity; this has been attributed to an increase in heat dissipation by brown adipose tissue. In contrast, mice bred to have an increased sense of smell increase their body weight in the absence of any change in food intake (Riera et al., 2017). These studies indicate that the olfactory system can regulate body weight by direct effects on energy expenditure rather than solely through changes in food intake. Surgically bypassing the duodenum and jejunum in mice has been shown to reduce the dopamine-stimulating and appetite enhancing effects of intragastric glucose.

\section{Studies in Humans}

Hedonic eating is the consumption of palatable foods beyond the need-based energy requirements of the organism and is prevalent in overweight and obese individuals (Clemmensen et al., 2017). The remarkable success of gastric bypass surgeries in controlling overweight has been attributed, in part, to a reduction in hedonic eating. Studies in humans have shown that Roux-en-Y gastric bypass patients are less preoccupied with eating and begin to prefer low calorie over high calorie more palatable foods (Ernest et al., 2009; Schultes et al., 2010; Ullrich et al., 2013).

\section{EXERCISE AND METABOLIC HOMEOSTASIS}

\section{Arcuate and Ventromedial Hypothalamic Nuclei \\ Studies in Rodents}

Eight-weeks of voluntary exercise has been shown to prevent obesity, hyperphagia, hyperleptinemia and glucose intolerance 
in young MC4R knockout mice; paradoxically, this effect was associated with increased NPY and decreased POMC and MC3R expression in arcuate nuclei (Haskell-Luevano et al., 2009). Others report similar findings in obese rodents who lost weight and had blunted appetites despite having elevated hypothalamic NPY levels (Bi et al., 2005; Kawaguchi et al., 2005; Wang et al., 2008). Although hypothalamic levels of NPY can be expected to increase in energy-deficient, weight loss $(\geq 30 \%)$, intensely exercising and food restricted rats, such was not the case in these studies, indicating that other factor(s) have overridden the orexigenic effects of NPY. In this regard, Kawaguchi and associates found that exerciserelated weight loss in rats was associated with both an increase in arcuate nuclei NPY and corticotropin-releasing factor (CRF) expression in dorsomedial nuclei; intracerebroventricular injection of a CRF antagonist attenuated the weight loss, suggesting that CRF was the cause of the exercise-associate anorexia (Kawaguchi et al., 2005). And Wang and associates measured hypothalamic concentrations of NPY and ghrelin in diet-induced obese rats after short-term and long-term treadmill exercises and found that although NPY hypothalamic concentrations increased following both exercise regimens, hypothalamic ghrelin levels fell. The authors concluded that the weight loss and reduced appetite seen in their exercising rats was due to reduced hypothalamic levels of ghrelin (Wang et al., 2008).

In leptin deficient mice and diet-induced obese rats, $1 \mathrm{~h}$ of swimming and treadmill running has been shown to suppress hyperphagia and restore total energy intake, in part by returning hypothalamic POMC mRNA levels to normal. Exercise also increased serum and hypothalamic levels of interleukin (IL)6; when injected into the third ventricle of obese rats, IL6 reduced food intake and restored the anorexigenic effects of insulin and leptin by promoting IL-10-mediated inhibition of $I_{K} B$ kinase $\beta / N_{-}{ }_{K} B$ signaling and $E R$ stress responses (Ropelle et al., 2010). Transforming growth factor (TGF)$\beta$, another antiinflammatory cytokine, has been shown to enhance fat oxidation by activating noradrenergic neurons in the ventromedial and paraventricular hypothalamic nuclei (Fujikawa et al., 2007).

Other studies have shown the beneficial effects of exercise on CNS responses to leptin or insulin. Krawczewski and co-authors found that voluntary exercise in a mouse strain susceptible to diet-induced obesity decreased fat mass \& increased energy expenditure via activation of leptin receptor-positive neurons in the ventromedial nucleus; in this study, intracerebral leptin did not decrease body weight or food intake in sedentary mice fed high fat diets but did reduce body weight in exercising mice. They concluded that exercise leads to the maintenance of a lower body weight and leaner composition by improving CNS leptin action in obese animals (Krawczewski Carhuatanta et al., 2011). Chiarreotto-Ropelle and co-authors found that exercise improved insulin and leptin signaling in obese rats by disrupting the interaction between hypothalamic protein tyrosine kinase phosphatase $\mathrm{B}$ with proteins involved in the early steps of insulin and leptin signaling (Chiarreotto-Ropelle et al., 2013) and Patterson and associates found that postweaning exercise in diet induced obese rats produced prolonged increases in central leptin sensitivity and signaling (Patterson et al., 2009). In this regard, Caruso and coauthors found that a short period of exercise early in life had lasting beneficial effects on body weight, adiposity and hormone profile of rats from obese mothers despite being followed by a period of inactivity (Caruso et al., 2013). Exercise has also been shown to increase the expression of BDNF in rodents (Araya et al., 2013).

\section{Studies in Humans}

High intensity exercise has been shown to reduce plasma levels of ghrelin and increase levels of GLP-1, BDNF, and GDF15; as previously noted, ghrelin exerts its orexigenic effects in part by activating AgRP/NPY neurons, and BDNF and GDF15 exert some of their anorexigenic effects by activating the melanocortin pathway.

Holliday and Blannin documented transient decreases in ghrelin and increases in GLP-1in 12 endurance trained men following $15-45 \mathrm{~min}$ of cycling at $\sim 76 \% \mathrm{VO}_{2 \mathrm{mx}}$; there was no change in appetite, but relative energy intake (intakeexpenditure) was reduced (Holliday and Blannin, 2017). Similar findings were reported by Douglas and associates in a study involving 15 healthy men who ran for $60 \mathrm{~min}$ on treadmills at $\sim 70 \% \mathrm{VO}_{2 \mathrm{mx}}$; exercise elicited a high level of energy expenditure $(7,566 \pm 635 \mathrm{~kJ})$ but did not produce compensatory changes in appetite or energy intake (Douglas et al., 2015). Kojima and associates found that a $20-\mathrm{km}$ run done by well-trained longdistance runners decreased plasma ghrelin levels and energy intake as compared to non-exercising controls (Kojima et al., 2016). Broom et al. conducted a study in which nine healthy men ran for $55 \mathrm{~min}$ at $52 \%$ peak oxygen uptake $\left(\mathrm{VO}_{2 \text { peak }}\right)$ or $36 \mathrm{~min}$ at $75 \% \mathrm{VO}_{2 \text { peak }}$ and another nine men ran for 45 or $90 \mathrm{~min}$ at $70 \% \mathrm{VO}_{2 \text { peak }}$; in both groups, plasma levels of acylated ghrelin and hunger ratings fell and remained suppressed for up to $1.5 \mathrm{~h}$ (Broom et al., 2017). Importantly, high intensity interval training (15 second sprints at $170 \% \mathrm{VO}_{2 \max }$ with 60 second periods of active recovery at $32 \% \mathrm{VO}_{2 \max }$ ) is reported to decrease ghrelin levels and energy intake in obese subjects (Sim et al., 2014).

Araya et al. found that 30 sessions of aerobic exercise done by 15 overweight subjects increased their serum BDNF levels (Araya et al., 2013). Galliera and associates found that high intensity exercise elevated circulating levels of GDF15 in elite rugby players, presumably by activating ROS and ER-stress pathways (Galliera et al., 2014). In a study involving seven healthy males exercising at $67 \%$ of their VO2max, Kleinert et al. found that plasma GDF15 levels increased 34\% immediately after exercise and by $64 \%$ above resting values $120 \mathrm{~min}$ after cessation of exercise (Kleinert et al., 2018). And serum BDNF rose significantly in 14 elderly women following a 16-week aquarobic exercise program (Kim and Kim, 2018).

Although exercise reduces leptin levels in proportion to the triglyceride content of white adipose tissue in obese individuals (Leal-Cerrro et al., 1998), evidence in humans to support the role of exercise in reducing obesity-related leptin resistance is lacking. 


\section{Area Postrema, Nucleus Tractus Solitarius, Parabrachial Nucleus, and Vagus \\ Studies in Rodents}

Using immunochemical labeling of the protein product of the proto-oncogene $c$-fos in rat brains, Iwamoto, and associates found that treadmill exercise resulted in increased labeling (i.e., potential gene activation) of areas involved in autonomic nervous system and somatomotor control, including the parabrachial nucleus, the medial portion of the NTS, and medullary areas containing the area postrema (Iwamoto et al., 1996). Barna and associates found similar $c$-fos labeling of diencephalic and brainstem areas in exercising rats (Barna et al., 2012).

\section{Studies in Humans}

As previously noted, high intensity exercise can reduce plasma levels of ghrelin and increase levels of BDNF and GDF15, all of which act on brainstem neurons to enhance (ghrelin) or reduce (BDNF, GDF15) food intake. High intensity exercise can also cause transient increases in plasma levels of the gut hormones GLP-1, PP, and PYY (Martins et al., 2007) whose appetitesuppressing effects are mediated by afferent vagal neurons. Importantly, GLP-1 binding induces an anorexigenic phenotype in afferent vagal neurons, an effect that is down-regulated by ghrelin (Ronveaux et al., 2015).

\section{Midbrain and Limbic System Studies in Rodents}

Activation of neurons expressing D1 and D2 dopamine receptors in the nucleus accumbens has been shown to regulate voluntary running, locomotion, and food intake in rodents (Zhu et al., 2016). And voluntary wheel running in exercise-habituated rats has been shown to be dependent on both the nucleus accumbens and the medial prefrontal cortex (Basso and Morrell, 2015). Chen et al. reported that moderate intensity treadmill exercise decreased the preference of diet-induced obese mice for highfat diets as compared to non-exercising controls; they provided evidence that this change in food preference was associated with dopamine plasticity in the mesoaccumbens dopamine system (Chen et al., 2017).

\section{Studies in Humans}

Panek and associates found that moderate intensity exercise done 3-5 days per week by previously inactive human subjects reduced the reinforcing value (motivation to eat) of high energy density foods, although it had no effect on food preferences. It is not known whether ghrelin, which binds to GHSRs in the amygdala and dopaminergic neurons, played a role in this effect (Panek et al., 2014).

\section{SUMMARY POINTS}

1. Leptin is produced in adipocytes and reduces appetite and weight gain by inhibiting AgRP/NPY neurons and stimulating POMC/CART neurons in the hypothalamic arcuate nucleus. In rodents, obesity is associated with leptin resistance due to decreased mRNA expression and translation of its receptor. It is unclear as to why leptin resistance exists in obese humans, although elevated levels seen in overweight individuals may be rendered ineffective by SOCS-3. Exercise reduces leptin levels in proportion to reductions in triglyceride stores in white adipose tissue.

2. Ghrelin is produced by endocrine cells in the gastric mucosa, and exerts orexigenic effects by binding to GHSRs expressed by AgRP/NPY neurons in the hypothalamus and by neurons in the area postrema. Ghrelin also binds to midbrain dopaminergic neurons mediating homeostatic feeding and food-reward behavior, and neurons in the hippocampus and amygdala that mediate more complex behaviors related to food intake. Baseline plasma ghrelin levels are inversely proportion to body weight. High intensity exercise reduces ghrelin levels and energy intake in obese and normal weight subjects.

3. GLP-1 is produced by intestinal L-cells. It reduces appetite by inducing an anorexic phenotype in vagal afferent neurons; GLP-1 expressing neurons in the medulla also send anorexigenic signals to the paraventricular nucleus of the hypothalamus. Plasma GLP-levels are depressed in obese individuals. High intensity exercise causes transient rises in GPL-1 blood levels in both obese and normal weight individuals. GLP-1 and GLP-1 analogues are effective in reducing hunger scores and weight when given to rodents and humans, and GLP-1 is a potent incretin, forming the basis for new treatments of diabetes mellitus.

4. BDNF is widely distributed in the brain. It exerts its anorexigenic effects by binding to $\operatorname{TrkB}$ receptors which are highly expressed in POMC/CART neurons, and in neurons in the area postrema, NTS, and dorsal motor nucleus of the vagus. Genetic polymorphisms in BDNF are associated with hyperphagic obesity. Serum BDNF levels may be low in overweight diabetic subjects. High intensity exercise can increase BDNF blood levels.

5. GDF15 is an inflammatory cytokine found in high levels in type 1 macrophages. GDF15 exerts its anorexigenic effects by binding to its receptor GD15AL expressed by POMC/CART neurons and by neurons in the area postrema, and parabrachial and central amygdala nuclei. Vigorous submaximal exercise has been shown to increase GDF15 serum levels in humans.

6. Gut peptide hormones (cholecystokinin, amylin, PP, and PYY) exert their anorexigenic effects in the area postrema, NTS, and dorsal motor nucleus of the vagus. Blood levels of PP and PYY may increase transiently following high intensity exercise.

7. Following bariatric surgery the vagal NTS and vaso-vagal pathways play a major role in restoring normal function to the pancreas (normalizing insulin secretion, reducing glucagon production), liver (recovering insulin sensitivity, reducing gluconeogenesis and free fatty acid release), and gastrointestinal tract (reducing ghrelin secretion, restoring normal responses to nutrients, peptides, hormones).

Please see Table 1 and Figure 1 for a more comprehensive summary of the effects of obesity, high fat-high energy diets and exercise on the central nervous system control of energy 
TABLE 1 | CNS control of metabolic homeostasis.

\begin{tabular}{|c|c|c|c|c|}
\hline Structure & Neurons, receptors & $\begin{array}{l}\text { Effect on energy } \\
\text { intake/expenditure }\end{array}$ & $\begin{array}{l}\text { Function in obesity or high } \\
\text { fat/energy diet }\end{array}$ & Effect of exercise \\
\hline $\begin{array}{l}\text { HYPOTHALAMUS } \\
\text { arcuate \& ventromedial } \\
\text { nuclei }\end{array}$ & $\begin{array}{l}\text { AgRP/NPY neurons } \\
\text { POMC/CART neurons } \\
\text { MC3R, MC4R }\end{array}$ & $\begin{array}{l}\text { Orexigenic, } \downarrow \text { energy expenditure } \\
\text { Anorexigenic } \\
\text { Anorexigenic, } \\
\uparrow \text { energy expenditure }\end{array}$ & $\begin{array}{l}\text { Resistant to suppression by } \\
\text { leptin, insulin; } \downarrow \text { synapses. } \\
\text { Resistant to activation by leptin, } \\
\text { suppression by NPY, } \downarrow \\
\text { neurogenesis } \\
\text { MC4R loss causes hyperphagic } \\
\text { obesity, insulin resistance }\end{array}$ & $\begin{array}{l}\downarrow \text { insulin, leptin resistance, } \uparrow \text { leptin } \\
\text { receptor expression, transmission, } \\
\downarrow \text { ghrelin in hypothalamus } \\
\downarrow \text { leptin resistance, } \\
\text { Prevents hyperphagic obesity in } \\
\text { young MC4R }-/- \text { mice }\end{array}$ \\
\hline $\begin{array}{l}\text { MIDBRAIN } \\
\text { meso-accumbens } \\
\text { dopamine system }\end{array}$ & $\begin{array}{l}\text { D1R, D2R, MC4R, } \\
\text { GHSR }^{+} \text {neurons }\end{array}$ & $\begin{array}{l}\text { Regulate voluntary food intake } \\
\text { and energy expenditure (running, } \\
\text { locomotion). }\end{array}$ & $\begin{array}{l}\downarrow \text { energy expenditure due to } \downarrow \\
\mathrm{D} 2 \mathrm{R}+\text { neuron signaling in } \\
\text { nucleus accumbens }\end{array}$ & $\begin{array}{l}\text { Short-term anorexia, } \downarrow \text { weight if } \\
\text { energy expenditure }>\text { intake }\end{array}$ \\
\hline $\begin{array}{l}\text { PONS } \\
\text { parabrachial nucleus }\end{array}$ & $\begin{array}{l}\text { Calcitonin gene-related } \\
\text { peptide }^{+} \text {neurons }\end{array}$ & $\begin{array}{l}\text { Primarily anorexigenic (taste } \\
\text { aversions, taste preferences). }\end{array}$ & $\begin{array}{l}\downarrow \text { taste response to sucrose in } \\
\text { CCK-1R }-/ \text { - obese mice }\end{array}$ & $\begin{array}{l}\uparrow \text { ANS and somatosensory gene } \\
\text { expression }\end{array}$ \\
\hline $\begin{array}{l}\text { MEDULLA } \\
\text { area postrema, NTS, \& } \\
\text { vagus* }^{*}\end{array}$ & $\begin{array}{l}\text { GDF15R+, } \\
\text { MC4R } \\
\text { ANS } \\
\text { neurons }\end{array}$ & $\begin{array}{l}\text { Orexigenic signals: ghrelin } \\
\text { Anorexigenic signals: leptin, } \\
\text { CCK, GLP-1, PYY, GDF15, } \\
\text { BDNF }\end{array}$ & $\begin{array}{l}\text { Impaired anorexigenic signals \& } \\
\text { circadian rhythms in NTS }\end{array}$ & $\begin{array}{l}\uparrow \text { SNS-mediated energy expenditure; } \\
\downarrow \text { ghrelin signaling, } \uparrow \text { GDF15 signaling }\end{array}$ \\
\hline $\begin{array}{l}\text { DIENCEPHALON } \\
\text { olfactory bulb }\end{array}$ & Olfactory nerves & $\begin{array}{l}\text { Anosmia: anorexigenic; } \uparrow \text { energy } \\
\text { expenditure Hyperosmia: } \\
\text { orexigenic; } \downarrow \text { energy expenditure }\end{array}$ & $\begin{array}{l}\text { Enhanced sense of smell, } \\
\uparrow \text { appetite, } \downarrow \text { energy expenditure }\end{array}$ & Unknown \\
\hline
\end{tabular}

*The vagal nucleus tractus solitarius and vaso-vagal pathways play a preeminent role in the rapid \& often persistent remission of type 2 diabetes and the metabolic syndrome in persons

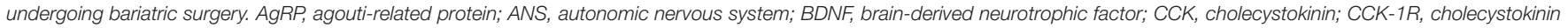

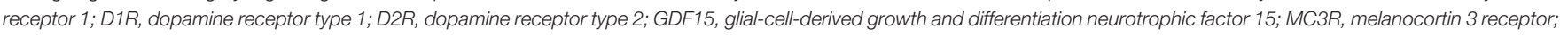
MC4R, melanocortin 4 receptor; NPY, neurotropin Y; NTS, nucleus tractus solitarius; POMC, pro-opiomelanocortin; SNS, sympathetic nervous system.

homeostasis. This review does not include the important contributions made by peripheral tissues (e.g., myokines, adipokines other than leptin, and irisin) to energy homeostasis.

\section{DISCUSSION}

In their review of 16 cohort studies involving 120,813 adults from Europe and the United States, Kivimäki and associates found that the risk of developing cardiometabolic multimorbidity (i.e., having at least two of the following disorders: type 2 diabetes, coronary heart disease, or stroke) was twice as high in overweight individuals (BMI $25.0-29.9 \mathrm{~kg} / \mathrm{m}^{2}$ ), nearly five times as high in persons with class 1 obesity $\left(30.0-34.9 \mathrm{~kg} / \mathrm{m}^{2}\right)$, and nearly fifteen times as high in persons with class $2 / 3$ obesity (BMI > $35.0 \mathrm{~kg} / \mathrm{m}^{2}$ ) when compared to normal weight controls. Severely obese individuals were particularly prone to develop diabetes mellitus followed by a vascular event (Kivimäki et al., 2017).

These frightening statistics are a reflection of man's recent success in developing a world rich in hedonic temptations and in technologies that favor indolence over exercise; coupled with the snail's pace of genetic mutations that might allow us to adapt to this world of affluence, our very survival as a species isin a real sense-dependent on our conscious effort to develop healthful life style changes. What was once a survival benefit (e.g., being able to store energy in fat and tolerate low temperatures by increasing body surface area) has become a survival risk for many of us.

Whereas physical exercise may cause anorexia and weight loss by decreasing plasma levels of ghrelin and/or increasing levels of BDNF, GDF15, GLP-1, and other gut-derived hormones, the effects are usually transient and only associated with weight loss when the exercise is sufficiently taxing to create an energy loss that exceeds energy intake; this may require achieving a $\mathrm{VO}_{2 \text { peak }}$ of at least $60 \%$ for a protracted period of time (Broom et al., 2017) - goals seldom achieved in morbidly obese individuals. In obese individuals leptin loses its ability to suppress appetite and increase energy expenditure for reasons that are not fully understood, and midbrain dopamine and limbic centers that normally regulate voluntary motion and food reward signals appear deficient in their ability to control the physical malaise and hedonic eating that characterizes the obese state. On the other hand, GLP-1, a potent anorectic and incretin, has emerged as a promising treatment for both obesity and diabetes mellitus (Näslund et al., 2004). And Blasi has emphasized the importance of the area postrema and the vagal nucleus tractus solitarius in restoring normal function to the pancreas, liver, and gastrointestinal tract following bariatric surgery (Blasi, 2016).; it is no coincidence that this same medullary region plays a major role in transducing orexigenic signals from ghrelin and anorexigenic signals from BDNF, GDF15, and the intestinal hormones GLP-1, cholecystokinin, amylin, PP, and PYY (Wren, 2008; Clemmensen et al., 2017); see Table 1 and Figure 1.

Finally, the full extent of the effect of exercise on the central nervous system is as yet to be determined. Parker and associates measured blood levels of low molecular weight endogenous peptides (the plasma peptidome) in four healthy men undergoing a two-phase exercise regimen: cycling for $6 \mathrm{~min}$ at $77 \% \mathrm{VO}_{2 \max }$ and then to exhaustion at $87-88 \%$ $\mathrm{VO}_{2 \max }$. They found that this exercise program rapidly modulated circulating levels of 425 bioactive peptides through a network of proteases and post-translational modifications, findings that emphasize the extreme complexity of the effects of exercise on the control of metabolic homeostasis (Parker et al., 2017). 


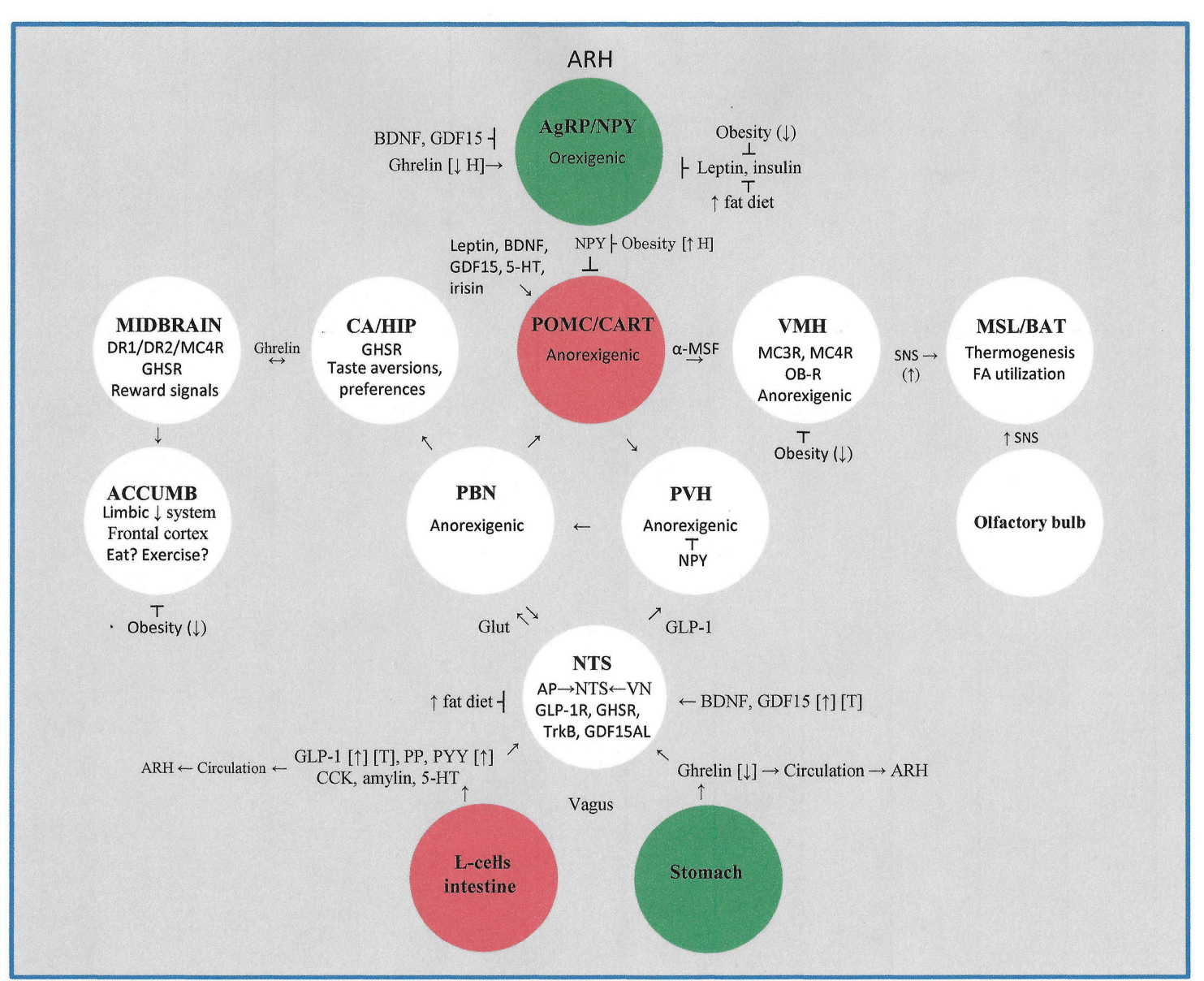

FIGURE 1 | This figure illustrates the major hypothalamic, midbrain, pontine, limbic system, brainstem, and gastrointestinal systems that contribute to the control of energy homeostasis. The impact of obesity, high fat- high energy diets, and moderate to vigorous intensity exercise on energy homeostasis is detailed. Not included is the lateral hypothalamic area which plays an important role in receiving sensory signals from the intestinal tract and liver. ACCUMB, nucleus accumbens; AgRP, agouti-related protein; $\alpha-M S F$, alpha-melanocortin stimulating factor; AP, area postrema; ARH, arcuate hypothalamus; BAT, brown adipose tissue; BDNF, brain-derived neurotrophic factor; CA, central amygdala; CART, cocaine and amphetamine-regulated transcripts; CCK, cholecystokinin; D1R, dopamine receptor type 1; D2R, dopamine receptor type 2; GDF15, glial-cell-derived growth and differentiation neurotrophic factor 15; GDF15AL, GD15F receptor; GHSR, growth hormone secretagogue receptor (for ghrelin); Glut, glutamine; HIP, hippocampus; MC3R, melanocortin 3 receptor; MC4R, melanocortin 4 receptor; MSL, muscle; NPY, neurotropin Y; NTS, nucleus tractus solitarius; OB-R, leptin receptor; PP, pancreatic peptide; PYY, peptide YY; PBN, parabrachial nucleus; PVH, paraventricular hypothalamus; POMC, pro-opiomelanocortin; SNS, sympathetic nervous system; TrkB, BDNF receptor; VN, vagus nucleus; VMH, ventral medial hypothalamus. Symbols: [ $\uparrow]$, exercise increases blood levels; $[\downarrow]$, exercise decreases blood levels; $\rceil]$, therapeutic potential; $(\uparrow H)$, exercise increases hypothalamic levels; $(\downarrow)$, exercise decreases effect.

\section{FUTURE DIRECTIONS}

Further research is needed to determine the safety and efficacy of anorexigenic peptides such as GLP-1 and GLP-1 analogs, GDF15, and BDNF in inducing weight loss in obese individuals. Trials of exercise training done in low temperature environments, where energy demands are inherently higher, should be assessed. Studies should be done to determine whether exercise training done early in life causes epigenetic changes that have long term beneficial effects on CNS regulation of metabolic homeostasis. Efforts should be made to find medications that can safely downregulate hedonic dietary habits. And, in accordance with World Health Organization recommendations, all school systems should include programs that require children and adolescents to participate in activities that allow them to accumulate at least 60 min of moderate to intense physical activity daily.

\section{AUTHOR CONTRIBUTIONS}

JS is the author of this manuscript and takes sole responsibility for the accuracy of its content.

\section{ACKNOWLEDGMENTS}

The author is appreciative of the support provided by the Department of Academic Affairs. 


\section{REFERENCES}

Araya, A. V., Orellana, X., Godoy, D., Soto, L., and Fiedler. J. (2013). Effect of exercise on circulating levels of brain-derived neurotrophic factor (BDNF) in overweight and obese subjects. Horm. Metab. Res. 45, 541-544. doi: $10.1055 / \mathrm{s}-0032-1333237$

Arkan, M. C., Hevener, A. L., Greten, F. R., Maeda, S., Li, Z.-W., Long, J. M., et al. (2005). INK- $\beta$ links inflammation to obesity-induced insulin resistance. Nat. Med. 11, 191-198. doi: 10.1038/nm1185

Barna, B. F., Takakura, A. C., and Moreira, T. S. (2012). Pontomedullary and hypothalamic distribution of Fos-like immunoreactive neurons after acute exercise in rats. Neuroscience 212, 120-130. doi: 10.1016/j.neuroscience.2012.03.039

Basso, J. C., and Morrell, J. I. (2015). The medial prefrontal cortex and nucleus accumbens mediate the motivation for voluntary wheel running in the rat. Behav. Neurosci. 129, 457-471. doi: 10.1037/bne0000070

Baver, S. B., Hope, K., Guyot, S., Bjørbaek, C., Kaczorowski, C., and O'Connell, K. M. S. (2014). Leptin modulates the intrinsic excitability of AgRP/NPY neurons in the arcuate nucleus of the hypothalamus. J. Neurosci. 34, 5486-5496. doi: 10.1523/JNEUROSCI.4861-12.2014

Bi, S., Scott, K. A., Hyun, J., Ladenheim, E. E., and Moran, T. H. (2005). Running wheel activity prevents hyperphagia and obesity in otsuka longevans tokushima fatty rats: role of hypothalamic signaling. Endocrinology 146, 1676-1685. doi: 10.1210/en.2004-1441

Blasi, C. (2016). The role of the vagal nucleus tractus solitarius in the therapeutic effects of obesity surgery and other interventional therapies on type 2 diabetes. Obes. Surg. 26, 3045-3057. doi: 10.1007/s11695-016-2419-2

Broom, D. R., Miyashita, M., Wasse, L. K., Pulsford, R., King, J. A., Thackray, A. E., et al. (2017). Acute effect of exercise intensity and duration on acylated ghrelin and hunger in men. J. Endocrinol. 232, 411-422. doi: 10.1530/JOE-16-0561

Carter, M. E., Soden, M. E., Zweifel, L. S., and Palmiter, R. D. (2013). Genetic identification of a neural circuit that suppresses appetite. Nature 503, 111-114. doi: $10.1038 /$ nature 12596

Caruso, V., Bahari, H., and Morris, M. J. (2013). The beneficial effects of early short-term exercise in the offspring of obese mothers are accompanied by alterations in the hypothalamic gene expression of appetite regulators and FTO (fat mass and obesity associated) gene. J. Neuroendocrinol. 25, 742-752. doi: 10.1111/jne. 12053

Global Health Estimates (2015). Deaths by Cause, Age, Sex, by Country and by Region, 2000-2015. Geneva: World Health Organization.

Cavanaugh, A. R., Schwartz, G. J., and Blouet, C. (2015). High-fat feeding impairs nutrient sensing and gut brain integration in the caudomedial nucleus of the solitary tract in mice. PLOS ONE 10:e118888. doi: 10.1371/journal.pone.0118888

Chen, L., Magliano, D. J., and Zimmet, P. Z. (2011). The worldwide epidemiology of type 2 diabetes mellitus -present and future perspectives. Nat. Rev. Endocrinol. 8, 228-236. doi: 10.1038/nrendo.2011.183

Chen, W., Wang, H. J., Shang, N. N., Liu, J., Li, J., Tang, D. H., et al. (2017). Moderate intensity treadmill exercise alters food preference via dopaminergic plasticity of ventral tegmental area-nucleus accumbens in obese mice. Neurosci. Lett. 641, 56-61. doi: 10.1016/j.neulet.2017.01.055

Chiarreotto-Ropelle, E. C., Pauli, L. S. S., Katashima, C. K., Pimentel, G. D., Picardi, P. K., Silva, V. R. R., et al. (2013). Acute exercise suppresses hypothalamic PTP1B protein level and improves insulin and leptin signaling in obese rates. Am. J. Physiol. Endocrinol. Metab. 305, E649-E659. doi: 10.1152/ajpendo.00272.2013

Clemmensen, C., Müller, T. D., Woods, S. C., Berthoud, H.-R., Seeley, R. J., and Tschöp, M. H. (2017). Gut-brain cross-talk in metabolic control. Cell 168, 758-774. doi: 10.1016/j.cell.2017.01.025

de Git, K. C., and Adan, R. A. (2015). Leptin resistance in diet-induced obesity: the role of hypothalamic inflammation. Obes. Rev. 16, 207-224. doi: 10.1111/obr.12243

Demmier, K. M., Klasen, S., Nzuma, J. M., and Qaim, M. (2017). Supermarket purchase contributes to nutrition-related non-communicable diseases in urban Kenya. PLoS ONE 12:e0185148. doi: 10.1371/journal.pone. 0185148

Douglas, J. A., King, J. A., McFarlane, E., Baker, L., Bradley, C., Crouch, N., et al. (2015). Appetite, appetite hormone and energy intake responses to two consecutive days of aerobic exercise in healthy young men. Appetite 92, 57-65. doi: 10.1016/j.appet.2015.05.006

Ernest, B., Thurnheer, M., Wilms, B., and Schultes, B. (2009). Differential changes in dietary habits after gastric bypass versus gastric banding operations. Obes. Surg. 19, 274-280. doi: 10.1007/s11695-008-9769-3

Fox, E. A., Biddinger, J. E., Jones, K. R., McAdams, J., and Worman, A. (2013). Mechanism of hyperphagia contributing to obesity in brainderived neurotrophic factor knockout mice. Neurosci. 229, 176-199. doi: 10.1016/j.neuroscience.2012.09.078

Fujikawa, T., Matsumura, S., Yamada, H., Inoue, K., and Fushiki, T. (2007). Transforming growth factor-beta in the brain enhances fat oxidation via noradrenergic neurons in the ventromedial and paraventricular hypothalamic nucleus. Brain Res. 1173, 92-101. doi: 10.1016/j.brainres.2007.08.002

Galliera, E., Lombardi, G., Marazzi, M. G., Grasso, D., Vianello, E., Pozzoni, R., et al. (2014). Acute exercise in elite rugby players increases the circulating level of the cardiovascular biomarker GDF-15. Scan. J. Clin. Lab. Invest. 74, 492-499. doi: 10.3109/00365513.2014.905697

Garrison, J. L., and Knight, Z. A. (2017). Linking smell to metabolism and aging. Science 358, 718-719. doi: 10.1126/science.aao5474

Gavini, C. K., Jones, W. C., and Novak, C. M. (2016). Ventromedial hypothalamic melanocortin receptor activation: regulation of activity energy expenditure and skeletal muscle thermogenesis. J. Physiol. 594, 5285-5301. doi: 10.1113/JP272352

Greenberg, A. S., and Obin, M. S. (2006). Obesity and the role of adipose tissue in inflammation and metabolism. Am. J. Clin. Nutr. 83(Suppl.), 461S-465S. doi: 10.1093/ajcn/83.2.461S

Haqq, A. M., Farooqi, I. S., O’Rahilly, S., Stadler, D. D., Rosenfeld, R. G., and Pratt, K. L., et al. (2003). Serum ghrelin levels are inversely correlated with body mass index, age, and insulin concentrations in normal children and are markedly increased in Prader-Willi syndrome. J. Clin. Endocrinol. Metab. 88, 174-178. doi: $10.1210 /$ jc.2002-021052

Haskell-Luevano, C., Schaub, J. W., Andreasen, A., Haskell, K. R., Moore, M. C. Koerper, L. M., et al. (2009). Voluntary exercise prevents the obese and diabetic metabolic syndrome of the melanocortin-4 receptor knockout mouse. FASEB J. 23, 642-655. doi: 10.1096/fj.08-109686

Holliday, A., and Blannin, A. (2017). Appetite, food intake and gut hormone responses to intense aerobic exercise of different duration. J. Endocrinol. 235, 193-205. doi: 10.1530/JOE-16-0570

Horvath, T. L., Sarman, B., Garcia-Cáceres, C., Enriori, P. J., Sotonyi, P., Shanabrough, M., et al. (2010). Synaptic input organization of the melanocortin system predicts diet-induced hypothalamic reactive gliosis and obesity. Proc. Natl. Acad. Sci. U.S.A. 107, 14875-14880. doi: 10.1073/pnas.1004282107

Hsu, J.-Y., Crawley, S., Chen, M., Ayupova, D. A., Lindhout, D. A., Higbee, J., et al. (2017). Non-homeostatic body weight regulation through a brainstemrestricted receptor for GDF15. Nature 550, 255-259. doi: 10.1038/nature24042

Hussein, M. S., Abushady, M. M., Refaat, S., and Ibrahim, R. (2014). Plasma levels of glucagon-like peptide 1 in obese Egyptians with normal and impaired glucose tolerance. Arch. Med. Res. 45, 58-62. doi: 10.1016/j.arcmed.2013.10.012

Iwamoto, G. A., Wappel, S. M., Fox, G. M., Buetow, K. A., and Waldrop, T. G. (1996). Identification of diencephalic and brainstem cardiorespiratory areas activated during exercise. Brain Res. 726, 109-122. doi: 10.1016/0006-8993(96)00303-4

Joly-Amado, A., Cansell, C., Denis, R. G. P., Delbes, A.-S., Castel, J., and Luquet, S. (2014). The hypothalamic arcuate nucleus and the control of peripheral substrates. Best Pract. Res. Clin. Endocrinol. Metab. 28, 725-737. doi: 10.1016/j.beem.2014.03.003

Kaneko, K., Yamada, T., Tsukita, S., Takahashi, K., Ishigaki, Y., Oka, Y., et al. (2009). Obesity alters circadian expressions of molecular clock genes in the brainstem. Brain Res. 1263, 58-68. doi: 10.1016/j.brainres.2008.12.071

Katsurada, K., Maejima, Y., Nakata, M., Kodaira, M., Suyama, S., Iwasaki, Y., et al. (2014). Endogenous GLP-1 acts on paraventricular nucleus to suppress feeding: projection from nucleus tractus solitarius and activation of corticotropinreleasing hormone, nesfatin-1 and oxytocin neurons. Biochem. Biophys. Res. Commun. 451, 276-281. doi: 10.1016/j.bbrc.2014.07.116

Kawaguchi, M., Scott, K. A., Moran, T. H., and Bi, S. (2005). Dorsomedial hypothalamic corticotropin-releasing factor mediation of exercise-induced anorexia. Am. J. Physiol. Regul. Integr. Comp. Physiol. 288, R1800-R1805. doi: 10.1152/ajpregu.00805.2004 
Kim, J. H., and Kim, D. Y. (2018). Aquarobic exercises improve serum blood irisin and brain-derived neurotrophic factor levels in elderly women. Exp. Gerontol. 104, 60-65. doi: 10.1016/j.exger.2018.01.024

Kivimäki, M., Kuosoma, E., Ferrie, J. E., Luukkonen, R., Nyberg, S. T., Alfredsson, L., et al. (2017). Overweight, obesity, and risk of cardiometabolic multimorbidity: pooled analysis of individual-level data for 120813 adults from 16 cohort studies from the USA and Europe. Lancet 2, e277-e285. doi: 10.1016/S2468-2667(17)30074-9

Kleinert, M., Clemmensen, C., Sjøberg, K. A., Carl, C. S., Jeppesen, J. F., Wojtaszewski, J. F. P., et al. (2018). Exercise increases circulating GDF15 in humans. Mol. Metab. 9, 187-191. doi: 10.1016/j.molmet.2017.12.016

Kojima, C., Ishibashi, A., Ebi, K., and Goto, K. (2016). The effect of a $20 \mathrm{~km}$ run on appetite regulation in long distance runners. Nutrients 8:672. doi: 10.3390/nu8110672

Kovacs, P., and Hajnal, A. (2008). Altered pontine taste processing in a rat model of obesity. J. Neurophysiol. 100, 2145-2157. doi: 10.1152/jn.01359.2007

Krawczewski Carhuatanta, K. A., Demuro, G., Tschöp, M. H., Pfluger, P. T., Benoit, S. C., and Obici, S. (2011). Voluntary exercise improves high-fat diet-induced leptin resistance independent of adiposity. Endocrinology 152, 2655-2664. doi: 10.1210/en.2010-1340

Laslett, L. J., Alagona, P. Jr., Clark, B. A. III., Drozda, J. P. Jr, Saldivar, F., Wilson, S. R., et al. (2012). The worldwide environment of cardiovascular disease: prevalence, diagnosis, therapy, and policy issues: a report from the American College of Cardiology. J. Am. Coll. Cardiol. 60, S1-S49. doi: 10.1016/j.jacc.2012.11.002

Leal-Cerrro, A., Garcia-Luna, P. P., Astorga, R., Parejo, J., Peino, R., Diequez, C., et al. (1998). Serum leptin levels in male marathon athletes before and after the marathon run. J. Clin. Endocrinol. Metab. 83, 2376-2379.

Li, B., Lang, N., and Cheng, Z. F. (2016). Serum levels of brain-derived neurotrophic factor are associated with diabetes risk, complications, and obesity: a cohort study from Chinese patients with type 2 diabetes. Mol. Neurobiol. 53, 5492-5499. doi: 10.1007/s12035-015-9461-2

Liu, J., Conde, K., Zhang, P., Lilascharoen, V., Xu, Z., Kook, B., et al. (2017). Enhanced AMPA receptor trafficking mediates the anorexigenic effect of glucagon like peptide-1 in the paraventricular hypothalamus. Neuron. 96, 897-909. doi: 10.1016/j.neuron.2017.09.042

Macia, L., Tsai, V. W.-W., Nguyen, A. D., Johnen, H., Kuffner, T., Shi, Y.-C., et al. (2012). Macrophage inhibitory cytokine 1 (MIC-1/GDF15) decreases food intake, body weight and improves glucose tolerance in mice on normal and obesogenic diets. PLoS ONE 7:e34868. doi: 10.1371/journal.pone.0034868

Martins, C., Morgan, L. M., Bloom, S. R., and Robertson, M. D. (2007). Effects of exercise on gut peptides, energy intake and appetite. J. Endocrinol. 193, 251-258. doi: 10.1677/JOE-06-0030

Mason, B. L., Wang, Q., and Zigman, J. M. (2014). The central nervous system sites mediating the orexigenic actions of ghrelin. Annu. Rev. Physiol. 76, 519-533. doi: 10.1146/annurev-physiol-021113-170310

McNay, D. E. G., Briançon, N., Kokoeva, M. V., Maratos-Flier, E., and Flier, J. S. (2012). Remodeling of the arcuate nucleus energy-balance circuit is inhibited in obese mice. J. Clin. Invest. 122, 142-152. doi: 10.1172/JCI43134

Merlotti, C., Morabito, A., and Pontiroli, A. E. (2014). Prevention of type 2 diabetes; a systematic review and meta-analysis of different intervention strategies. Diabetes Obes. Metab. 16, 719-727. doi: 10.1111/dom.12270

Myers, M. G., and Olson, D. P. (2012). Central nervous system control of metabolism. Nature 491, 357-363. doi: 10.1038/nature11705

Näslund, E., King, N., Mansten, S., Adner, N., Holst, J. J., Gutniak, M., et al. (2004). Prandial subcutaneous injections of glucagon-like peptide-1 cause weight loss in obese human subjects. Br. J. Nutr. 91, 439-446. doi: 10.1079/BJN 20031064

Obici, S., Magrisso, I. J., Ghazarian, S. S., Shirazian, A., Miller, J. R., Loyd, C. M., et al. (2015). Moderate voluntary exercise attenuates the metabolic syndrome in melanocortin-4 receptor-deficient rats showing central dopaminergic dysregulation. Mol. Metab. 4, 692-705. doi: 10.1016/j.molmet.2015. 07.003

Panek, L. M., Jones, K. R., and Temple, J. L. (2014). Short term aerobic exercise alters the reinforcing value of food in inactive adults. Appetite 81, 320-329. doi: 10.1016/j.appet.2014.06.102

Parker, B. L., Burchfield, J. G., Clayton, D., Geddes, T. A., Payne, R. J., Kiens, B., et al. (2017). Multiplexed temporal quantification of exercise-regulated peptidome. Mol. Cell. Proteomics 16, 2055-2068. doi: 10.1074/mcp.RA117.000020

Patterson, C. M., Bouret, S. G., Dunn-Meynell, A. A., and Levin, B. E. (2009). Three weeks of postweaning exercise in DIO rats produces prolonged increases in central leptin sensitivity and signaling. Am. J. Physiol. Regul. Integr. Comp. Physiol. 296, R537-R548. doi: 10.1152/ajpregu.9085 9.2008

Riera, C. E., Tsaousidou, E., Halloran, J., Follett, P., Hahn, O., Pereira, M. M., et al. (2017). The sense of smell impacts metabolic health and obesity. Cell Metab. 26, 198.e5-211.e5. doi: 10.1016/j.cmet.2017.06.015

Ronveaux, C. C., Tomé, D., and Raybould, H. E. (2015). Glucagon-like peptide 1 interacts with ghrelin and leptin to regulate glucose metabolism and food intake through vagal afferent neuron signaling. J. Nutr. 145, 672-680. doi: $10.3945 /$ jn. 114.206029

Ropelle, E. R., Flores, M. B., Cintra, D. E., Rocha, G. Z., Pauli, J. R., Morari, J., et al. (2010). IL-6 and IL-10 anti-inflammatory activity links exercise to hypothalamic insulin and leptin sensitivity through IKK $\beta$ and ER stress inhibition. PLoS Biol. 8, 1-20. doi: 10.1371/journal.pbio.1 000465

Ruegsegger, G. N., and Booth, F. W. (2017). Running from disease: molecular mechanisms associating dopamine and leptin signaling in the brain with physical inactivity, obesity, and type 2 diabetes. Front. Endocrinol. 8:109. doi: 10.3389/fendo.2017.00109

Schultes, B., Ernst, B., Wilms, B., Thurnheer, M., and Hallschmid, M. (2010). Hedonic hunger is increased in severely obese patients and is reduced after gastric bypass surgery. Am. J. Clin. Nutr. 92, 277-283. doi: 10.3945/ajcn.2009.29007

Sim, A. K., Wallman, K. E., Fairchild, T. J., and Guelf, K. J. (2014). Highintensity intermittent exercise attenuates ad-libitum energy intake. Int. J. Obes. 38, 417-422. doi: 10.1038/ijo.2013.102

Spaeth, A. M., Kanoski, S. E., Hayes, M. R., and Grill, H. J. (2012). TrkB receptor signaling in the nucleus tractus solitarius mediates food intake-suppressive effects of hindbrain BDNF and leptin. Am. J. Physiol. Endocrinol. Metab. 302, E1252-E1260. doi: 10.1152/ajpendo.0002 5.2012

Tsai, V. W.-W., Manandhar, R., Jørgensen, S. B., Lee-Ng, K. K. M., Zhang, H. P., Marquis, C. P., et al. (2014). The anorectic actions of the TGF $\beta$ cytokine MIC-1/GDF15 require an intact brainstem area postrema and nucleus of the solitary tract. PLOS ONE 9:e100370. doi: 10.1371/journal.pone.01 00370

Tsai, V. W., Zhang, H. P., Manandhar, R., Lee-Ng, K. K. M., Lebhar, H., Marquis, C. P., et al. (2017). Treatment with the TGF-b superfamily cytokine MIC1/GDF15 reduces the adiposity and corrects the metabolic dysfunction of mice with diet-induced obesity. Int. J. Obes. 42, 561-571. doi: 10.1038/ijo. 2017.258

Ueda, S.-Y., Nakahara, H., and Miyamoto, T. (2013). Effects of exercise on glucagon-like peptide-1 (GLP-1). J. Phys. Fitness Sports Med. 2, 221-224. doi: $10.7600 /$ jpfsm.2.221

Ullrich, J., Ernst, B., Wilms, B., Thurnheer, M., and Schultes, B. (2013). Roux-en $\mathrm{Y}$ gastric bypass surgery reduces hedonic hunger and improves dietary habits in severely obese subjects. Obes. Surg. 23, 50-55. doi: 10.1007/s11695-0120754-5

Wang, J., Chen, C., and Wang, R.-Y. (2008). Influence of short- and long-term treadmill exercises on levels of ghrelin, obestatin and NPY in plasma and brain extraction of obese rats. Endocrine 33, 77-83. doi: 10.1007/s12020-0089056-Z

Ward, Z. J., Long, M. W., Resch, S. C., Giles, C. M., Cradock, A. L., and Gortmaker, S. L. (2017). Simulation of growth trajectories of childhood obesity into adulthood. New Engl. J. Med. 377, 2145-2153. doi: 10.1056/NEJMoa 1703860

Williams, K. W., Scott, M. M., and Elmquist, J. K. (2011). Modulation of the central melanocortin system by leptin, insulin, and serotonin: coordinated actions in a dispersed neuronal network. Eur. J. Pharmacol. 660, 2-12. doi: 10.1016/j.ejphar.2010.11.042

Williams, L. M. (2012). Hypothalamic dysfunction in obesity. Proc. Nutrit. Soc. 71, 521-533. doi: 10.1017/S002966511200078X

Wren, A. M. (2008). Gut and hormones and obesity. Front. Horm. Res. 36, 165-181. doi: $10.1159 / 000115364$ 
Wu, Q., Clark, M. S., and Palmiter, R. D. (2012). Deciphering a neuronal circuit that mediates appetite. Nature 483, 594-598. doi: 10.1038/nature10899

Zhang, Y., Rodrigues, E., Gao, Y. X., King, M., Cheng, K. Y., Erdös, B., et al. (2010). Pro-opiomelanocortin gene transfer to the NTS but not ARC ameliorates chronic diet-induced obesity. Neuroscience 169, 1662-1671. doi: 10.1016/j.neuroscience.2010.06.001

Zhu, X., Ottenheimer, D., and DiLeone, R. J. (2016). Activity of D1/2 receptor expressing neurons in the nucleus accumbens regulates running, locomotion, and food intake. Front. Behav. Neurosci. 10:66. doi: 10.3389/fnbeh.2016. 00066
Conflict of Interest Statement: The author declares that the research was conducted in the absence of any commercial or financial relationships that could be construed as a potential conflict of interest.

Copyright (๑) 2018 Smith. This is an open-access article distributed under the terms of the Creative Commons Attribution License (CC BY). The use, distribution or reproduction in other forums is permitted, provided the original author(s) and the copyright owner are credited and that the original publication in this journal is cited, in accordance with accepted academic practice. No use, distribution or reproduction is permitted which does not comply with these terms. 